\title{
The influence of perceptual organizing responses on recall
}

WILLARD F. HARLEY, Jr. ${ }^{1}$, UNIVERSITY OF CALIFORNIA, RIVERSIDE, CYNTHIA OLDFIELD WILSON ${ }^{2}$, UNIVERSITY OF CALIFORNIA, LOS ANGELES, AND RONALD A. COLE, UNIVERSITY OF CALIFORNIA, RIVERSIDE

This study was designed to explicate the results of a previous study conducted by Tresselt \& Mayzner (1960) on incidental learning. Their Ss were administered one of three tasks which were designed to elicit different perceptual organizing responses on a list of 100 words. The performance of Ss on a test of free recall of the words were clearly influenced by the tasks. These results were interpreted to be in support of the hypothesis that learning is a function of the type of organizing response made. However, the results were possibly confounded by the total time the words were studied, since Ss in each task worked at their own rate. This experiment followed the method used by Tresselt and Mayzner with a control for total time of study. An analysis of these results confirmed the interpretation of Tresselt and Mayzner. The implications were discussed.

Learning has been shown to be closely related to the reported organization of the materials to be learned (Mattocks, 1960; Williams, 1962; Martin, Boersma, \& Cox, 1965; Harley, 1967). The Ss recalling most in these experiments reported that they covertly orgnaized these materials. Not all types of organization, were equally efficient. In particular, integration of letters to form a word was more efficient than no integration, but integration and mediation (development of meaningful associations to the words) was more effective for learning than integration alone. If these differentially effective organizing responses influence recall, then tasks which require the same organization should result in the same amount of recall.

This prediction was partially confirmed by Tresselt \& Mayzner (1960) in a study of incidental learning. The Ss in their study were assigned to one of three tasks: (1) A vowel cross-out task where Ss were simply instructed to cross out vowels in the stimulus words; (2) a handwriting task where Ss copied each of the stimulus words; and (3) a concept-judging task where Ss were to judge the degree to which each stimulus was related to the concept "economic." Although none of the Ss tested tried to learn the materials used in the task, when asked to recall the words, Ss in the concept-judging task recalled more than those in the handwriting task, and the latter were able to recall more than those in the cross-out task.

These results appeared to demonstrate that the type of organizational response used influenced learning. However, in the Tresselt and Mayzner study, the total time of stimulus exposure was not necessarily the same between tasks. All the stimuli appeared together on a mimeographed sheet and Ss performed operations on the stimuli at their own rate. It is likely that Ss spent the most time studying the material in the concept-judging task, less time in the handwriting task, and least time in the vowel cross-out task. There is fairly conclusive evidence that the amount learned is a positive function of total amount of time the material is studied (Bugelski, 1962; Harley, 1965). Therefore, these results do not unambiguously support the organizing response hypothesis.

This experiment represented an attempt to clarify the interpretation of the results of the Tresselt and Mayzner study with a control for total learning time.

Subjects. Fifty-four undergraduate students from an introductory psychology course at the University of California, Santa Barbara, served as Ss.

Apparatus. A word list consisting of 50 words were randomly selected from the 100-word list used by Mayzner \& Tresselt (1960). The list of words was covered by a sheet of cardboard with a slot in its center $(1 \times 4 \mathrm{~cm})$. Only one word at a time could appear through the slot.

Procedure. The Ss were divided into three groups. Group 1 was instructed to cross out vowels in the words as they appeared. Group 2 was instructed to copy each of the words and Group 3 was instructed to judge the words on the basis of the concept "economic" on a 7-point scale. The instructions presented to each of the three groups were as follows:

Group 1. "This experiment consists of two parts, the first being a perceptual test. A sheet of paper containing 50 words will be placed in front of you and the words will be seen one at a time. While a word appears, you are to cross out all the vowels in the words. You will be given $6 \mathrm{sec}$ for each word. Be as careful as possible. Are you ready?"

Group 2. "This experiment consists of two parts, the first being a test in handwriting. A sheet of paper containing $\mathbf{5 0}$ words will be placed in front of you and the words will be seen one at a time. While a word appears, you are to copy it directly below the word, on the sheet of paper. You will be given $6 \mathrm{sec}$ for each word. Be as careful as possible. Are you ready?"

Group 3. "This experiment consists of two parts, the first being a test of conceptual development. A sheet of paper containing 50 words will be placed in front of you and the words will be seen one at a time. While a word appears, you are to judge the degree to which it belongs or could be included in the concept "economic" using a 7-point scale. If a word does not belong or belongs to a very small degree to the concept, the number 1 is to be used. The number 7 is to be used if you feel the word belongs completely or to a very large degree to the concept. The intermediate numbers 2 through 6 are to be used to express intermediate degrees of belonging or inclusion in the concept. Place each judged number directly below the word on the sheet of paper. You will be given $6 \mathrm{sec}$ for each judgment. Be as careful as possible. Are you ready?"

After completing the task, Ss were asked to write down as many of the words as they could recall. Ten $\min$ were given for the recall period, after which $S$ was asked if he had anticipated that he would be asked to recall the words. Six Ss who answered affirmatively were not considered in the analysis of the results.

Results. A one-way analysis of variance performed on the total number of items recalled by the $S s$ in Groups 1,2 , and 3 detected a significant task effect $(F=16.845$, df $=2 / 45, p<.01)$. The means and standard deviations of the number of words correct for Ss in the three groups together with those comparable data from the Tresselt and Mayzner study appear in Table 1. The withingroup variance was somewhat smaller in this study, but the means were quite similar to those obtained by Tresselt and Mayzner. The mean similarities were unexpected since only half of their words were used in this study. The smaller variance was attributed to the control of study duration.

Discussion. The results of this experiment support the findings of Tresselt and Mayzner. Differential recall was obtained even though the duration of stimulus exposure was constant across tasks. The effect may be justifiably attributed to the influence of organizing responses elicited by the individual tasks.

Our interpretation of these results is that the organization used in each of these tasks affects the nature of the stimulus percept. That is, the type of processing directly affects the perception of the stimulus. Crossing out vowels requires attending to individual letters in a word, a task of selective attention, where the percept held in memory is a series of individual letters. Writing the word, on the other hand, requires perceptual integration of letters. Not only is there a physical connecting of the letters, but writing is probably accompanied by covert pronunciation of the word itself. The percept in the writing task is probably some representation of the whole word. Finally, judging each word separately in relation to a concept involves the development of meaningful associations to aid classification. As different associations are made to a word held in memory, there is a modification of the existing percept. Thus, the organizational response elicited by each task directly affects the perception of the stimulus.

If the tasks are viewed as involving these basic organizational processes, the results of this study suggest that the more perceptual organization a stimulus receives, the better it is learned.

Table 1

Results of this study:

Results of Tresselt \& Mayzner (1960):

\begin{tabular}{lrrllrc} 
& \multicolumn{2}{c}{ Words Correct } & & \multicolumn{2}{c}{ Words Correct } \\
\cline { 2 - 5 } \multicolumn{1}{c}{ Task } & Mean & SD & & Task & Mean & SD \\
\hline Cross-out & 5.68 & 1.76 & & Cross-out & 4.30 & 3.00 \\
Handwriting & 8.94 & 3.61 & & Handwriting & 8.38 & 3.92 \\
Concept & 11.19 & 2.36 & & Concept & 16.86 & 7.20 \\
\hline
\end{tabular}


REFERENCES

BUGELSKI, B. R. Presentation time, total time, and mediation in pairedassociate learning. J. exp. Psychot., 1962, 63, 409-412.

HARLEY, W. F., Jr., Monetary incentive in paired-associate learning and its effect on learning strategies. Unpublished dissertation, University of California, Santa Barbara, 1967.

HARLEY, W. F., Jr., The effect of monetary incentive on paired-associate learning using an absolute method. Psychon. Sci., 1965, 3, 141-142.

MARTIN, C. J., BOERSMA, F. J., \& COX, D. L. A classification of associative strategies in paired-associate learning. Psychon. Sci., 1965, 3,
$455-456$

MATTOCKS, A. Referred to in B. J. Underwood \& R. W. Schulz (Eds.), Meaningfulness and verbal learning. Phitadelphia: Lippincott, 1960, 296-304.

TRESSELT, M. E., \& MAYZNER, M. S. A study of incidental learning. $J$. Psychol., 1960, 50, 339-347.

\section{NOTES}

1, 2. At the University of California, Santa Barbara, while this study was being conducted. 